\title{
(6) OPEN ACCESS \\ Intake of dietary fibre and lifetime non-steroidal anti- inflammatory drug (NSAID) use and the incidence of colorectal polyps in a population screened for colorectal cancer
}

\author{
Eileen Shaw, ${ }^{1}$ Matthew T Warkentin, ${ }^{1}$ S Elizabeth McGregor, ${ }^{2,3,4}$ Susanna Town, ${ }^{5}$ \\ Robert J Hilsden, ${ }^{2,5}$ Darren R Brenner ${ }^{1,2,3}$
}

${ }^{1}$ Department of Cancer Epidemiology and Prevention Research, CancerControl Alberta, Alberta Health Services, Calgary, Alberta, Canada ${ }^{2}$ Department of Community Health Sciences, Cumming School of Medicine, University of Calgary, Calgary, Alberta, Canada

${ }^{3}$ Department of Oncology, Cumming School of Medicine, University of Calgary, Calgary, Alberta, Canada ${ }^{4}$ Population, Public and Indigenous Health, Alberta Health Services, Calgary, Alberta, Canada ${ }^{5}$ Forzani and MacPhail Colon Cancer Screening Centre, Alberta Health Services, Calgary, Alberta, Canada

Correspondence to Dr Darren R Brenner, Department of Cancer Epidemiology and Prevention Research CancerControl Alberta, Alberta Health Services Holy Cross Centre, Calgary, Alberta T2S 3C3, Canada; Darren. Bre nner@albertahealthservices.ca

Received 2 November 2016 Revised 6 July 2017 Accepted 12 August 2017 Published Online First 28 August 2017

\section{ABSTRACT \\ Background There is suggestive evidence that} increased intake of dietary fibre and the use of nonsteroidal anti-inflammatory drugs (NSAIDs) are generally associated with decreased colorectal cancer risk. However, the effects on precursors of colorectal cancer, such as adenomatous polyps, are mixed. We present the associations between dietary fibre intake and NSAID use on the presence and type of colorectal polyps in a screening population.

Methods A cross-sectional study of 2548 individuals undergoing colonoscopy at the Forzani \& MacPhail Colon Cancer Screening Centre (Calgary, Canada) was conducted. Dietary fibre intake and NSAID use were assessed using the Diet History Questionnaire I or II and the Health and Lifestyle Questionnaire. Colorectal outcomes were documented as a polyp or high-risk adenomatous polyp (HRAP; villous histology, high-grade dysplasia, $\geq 10 \mathrm{~mm}$ or $\geq 3$ adenomas). Crude and ORs and $95 \%$ Cls were estimated using unconditional logistic regression.

Results There were 1450 negative colonoscopies and 1098 patients with polyps, of which 189 patients had HRAPs. Total dietary fibre intake was associated with a decreased presence of HRAPs (OR $=0.50,95 \% \mathrm{Cl}: 0.29$ to 0.86$)$ when comparing the highest to lowest quartiles and was observed with both soluble $(\mathrm{OR}=0.51,95 \% \mathrm{Cl}$ : 0.30 to 0.88$)$ and insoluble (OR=0.51, 95\% Cl: 0.30 to 0.86 ) fibres. Ever use of NSAIDs was also inversely associated with HRAPs (OR=0.65, 95\% Cl: 0.47 to 0.89 ), observed with monthly $(\mathrm{OR}=0.60,95 \% \mathrm{Cl}: 0.37$ to 0.95$)$ and daily (OR=0.53, 95\% Cl: 0.32 to 0.86$)$ use.

Conclusions Dietary fibre intake and NSAID use were associated with a decreased risk of having a HRAP at screening.

\section{INTRODUCTION}

Colorectal cancer remains the third most commonly diagnosed cancer in Canada and is the second leading cause of cancer mortality. ${ }^{1}$ Increased dietary fibre intake has been associated with a decreased risk of colorectal cancer in a systematic review and meta-analysis ${ }^{2}$; however, results have not been consistent as a large pooled analysis of 13 prospective cohorts did not observe a significantly reduced risk of colorectal cancer associated with increased dietary fibre intake after adjustment for other factors. ${ }^{3}$ The hypothesised mechanisms by which fibre protects against colorectal cancer include increasing stool bulk, decreasing transit time and reducing exposure to carcinogens. ${ }^{4}$ Similarly, there is some evidence that long-term use of low-dose aspirin can be protective against long-term incidence of colorectal cancer. ${ }^{5}$ Non-steroidal anti-inflammatory drugs (NSAIDs) are thought to aid in colorectal cancer prevention by acting on cyclooxygenase enzymes, which occur in increased concentrations in colorectal cancers, ${ }^{6}$ and inhibition by NSAIDs can result in apoptosis.

There has been an increasing amount of evidence for the roles of dietary fibre and NSAID use on the incidence of colorectal polyps, a precursor of colorectal cancer, ${ }^{8}{ }^{9}$ although findings have been mixed. With respect to dietary fibre, evidence from observational studies (predominantly case-control) indicates a reduced risk of colorectal adenomas with increased fibre. ${ }^{10-12}$ Two large randomised controlled trials of dietary interventions (the Wheat Bran Fiber Trial and the Polyp Prevention Trial) did not show any association between high fibre intake and recurrent adenomas in individual analysis ${ }^{13}{ }^{14}$; however, a pooled analysis revealed a statistically significant protective effect of increased fibre intake on adenoma recurrence in men. ${ }^{15}$ Studies have also demonstrated a protective role for NSAID use and colorectal adenomas, with the strongest evidence pointing to reduced polyp progression and recurrence with continued use of aspirin, ${ }^{516}$ but there is sparse evidence suggesting that aspirin use can lead to reduced long-term adenoma incidence. ${ }^{1017}$

In the present analysis, we investigated the role of dietary fibre intake (total, soluble and insoluble) and NSAID use (frequency and duration) on the presence and type of colorectal polyps in a population undergoing colorectal cancer screening in Calgary, Alberta, Canada.

\section{METHODS \\ Study population}

The study population was selected from the Forzani \& MacPhail Colon Cancer Screening Centre (CCSC) Biorepository in Calgary. The biorepository is housed within Alberta Health Services and includes a cohort of patients that underwent a screening-related colonoscopy between 2008 and 2015. The CCSC participants included in 


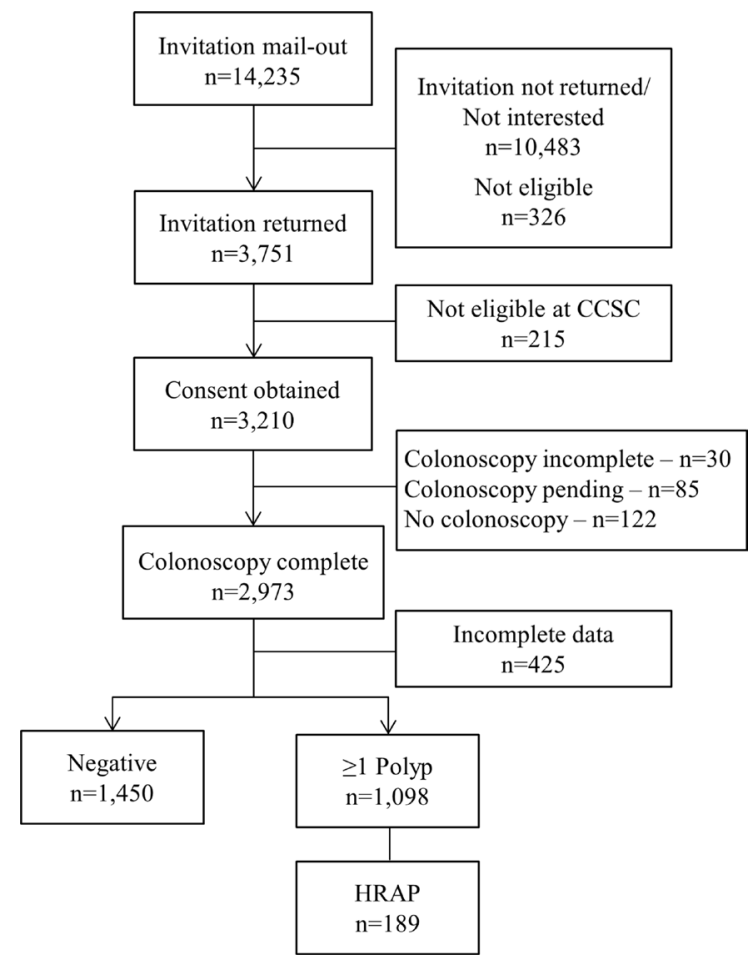

Figure 1 Recruitment flow diagram and selection of analytical sample population, $n=2548$. CCSC, Colon Cancer Screening Centre; HRAP, highrisk adenomatous polyp.

this study are residents of Calgary and Southern Alberta. The population includes individuals at an elevated risk for colorectal cancer, including those with a family history of colorectal cancer (first-degree relative), history of polyps or those referred to the clinic following a positive faecal immunochemical test (FIT) or faecal occult blood (FOB) test, in addition to those at average risk, aged 50-74 years, as per the Alberta Colorectal Cancer Screening Program guidelines. ${ }^{18}$ Average risk participants were identified through invitation letters to those on the waitlist for the CCSC following referral from their family doctor. Elevated risk individuals with a positive FIT/FOB test were invited to participate at the time of their consultation visit to the CCSC. All participants provided their informed consent. In total, 2548 participants are included within the study population.

\section{Data collection}

Fibre intake and frequency and duration of NSAID use were collected using the Diet History Questionnaire (DHQ) ${ }^{19}$ or $\mathrm{II}^{20}$ and the Health and Lifestyle Questionnaire (HLQ), respectively, which were completed prior to colonoscopy. Fibre intake (g/day) was estimated as total dietary fibre intake and broken down into soluble and insoluble fibres using the Diet*Calc software from the National Cancer Institute (V.1.4.3 for the DHQ-I and V.1.5.0 for the DHQ-II). The HLQ assessed the use of all NSAIDs, including diclofenac, etodolac, flurbiprofen, ibuprofen, indomethacin, ketoprofen, ketorolac, mefenamic acid, nabumetone, naproxen, piroxicam, sulindac and tiaprofenic acid. Self-reported lifetime duration (years) of daily, weekly, monthly and less than monthly NSAID use was used to estimate lifetime daily dose-years of NSAIDs, with one daily dose-year representing NSAID use every day for 1 year. Less than monthly, monthly and weekly NSAID use durations (years) were averaged for frequency of monthly/ weekly use and multiplied by appropriate factors representing
1 day. These were then summed with duration (years) of daily use to obtain daily dose-years of NSAID use.

Total, soluble and insoluble dietary fibre intakes were then categorised into quartiles for the entire analytical study population. Daily dose-years of non-zero NSAID use were categorised into tertiles and compared with no NSAID use for the entire study population. The HLQ was used to collect participant data on health, comorbidities, alcohol consumption, smoking and demographic details, such as gender and ethnicity (white, aboriginal, black, East Asian, mixed race, South Asian and other non-white).

Colonoscopy report forms (CRFs) were used to document data on each patient's baseline colonoscopy procedure. The quality of bowel preparation, depth of the scope, abnormalities identified and procedural time were documented at both baseline and at any follow-up procedure occurring within 6 months of the index procedure. Polyp data was similarly documented at baseline and recorded after the patient's baseline scope, which documented polyps and the associated pathology data from the CRFs. Polyps were defined as any polyp (hyperplastic, serrated and adenomatous) with pathological findings, including those not classifiable based on histology and those that were lost/ destroyed during the procedure, but excludes those with a pathology finding of normal or inflammatory. High-risk adenomatous polyps (HRAPs) were defined as adenomas with villous histology, high-grade dysplasia, $\geq 10 \mathrm{~mm}$ or $\geq 3$ polyps.

A total of 3210 participants were recruited from the screening programme at the CCSC (figure 1), with 2973 participants receiving a complete colonoscopy. After excluding participants with incomplete data for any relevant colon outcome variables or covariates, a total of 2548 participants were included in our analytical study population. A further 354 participants were excluded from the dietary fibre analyses due to missing data from the DHQ-II, resulting in 2194 participants for these analyses. There were 1450 negative colonoscopies and 1098 patients with at least one polyp (adenomatous, $n=773$; hyperplastic, $\mathrm{n}=383$ and serrated, $\mathrm{n}=189$ ), of which 189 patients had HRAPs.

\section{Statistical analyses}

Descriptive statistics were calculated for participants with and without polyps or adenomas and who had complete data for all demographics and exposures (dietary fibre intake: $n=2194$ and NSAID: $n=2548$ ). Contingency table analyses were generated for categorical variables and assessed for differences in distributions using Pearson's $\chi^{2}$ test of independence. Univariable and multivariable unconditional logistic regression models were used to evaluate crude and adjusted associations between fibre intake and NSAID use and colon outcomes, as defined by the presence of polyps or HRAPs. Adjusted models contained confounders defined a priori, including age, sex, body mass index (BMI), smoking status (never, former and current), reason for colonoscopy (average risk, FIT/FOB test-positive and family history) and family history of polyps (yes versus no), based on a literature review of the area and examination of the associations between exposures and outcomes of interest. Models for the dietary fibre intake analyses also adjusted for total daily caloric intake as a measure of total dietary volume. Potential effect modification of the association between fibre intake or NSAID use and the presence of polyps or HRAPs was assessed by testing for interaction by age, sex, BMI, ethnicity, smoking and reason for colonoscopy. Stratified analyses were performed for variables where statistically significant interactions were observed to identify any strata-specific effects of fibre intake or NSAID use on colon 
Table 1 Baseline characteristics of colorectal cancer screening population by outcome of polyps or high-risk adenomas $(n=2548)$

\begin{tabular}{|c|c|c|c|c|c|}
\hline \multirow{3}{*}{ Demographics } & \multirow[b]{2}{*}{ n } & \multicolumn{2}{|l|}{ Polyps } & \multicolumn{2}{|c|}{ High-risk adenomas } \\
\hline & & $\begin{array}{l}\text { No } \\
n=1450(57 \%)\end{array}$ & $\begin{array}{l}\text { Yes } \\
n=1098(43 \%)\end{array}$ & $\begin{array}{l}\text { No } \\
n=2359(93 \%)\end{array}$ & $\begin{array}{l}\text { Yes } \\
n=189(7 \%)\end{array}$ \\
\hline & & & & & \\
\hline \multicolumn{6}{|l|}{ Age (years) } \\
\hline$<40$ & 34 & $27(2 \%)$ & $7(1 \%)$ & $33(1 \%)$ & $1(1 \%)$ \\
\hline $40-49$ & 102 & $70(5 \%)$ & $32(3 \%)$ & $96(4 \%)$ & $6(3 \%)$ \\
\hline $50-59$ & 1169 & $713(49 \%)$ & $456(42 \%)$ & $1104(47 \%)$ & $65(34 \%)$ \\
\hline \multirow[t]{2}{*}{$60+$} & 1243 & $1450(44 \%)$ & $603(55 \%)$ & $1126(48 \%)$ & $117(62 \%)$ \\
\hline & & \multicolumn{2}{|c|}{$p^{*}<0.01$} & \multicolumn{2}{|c|}{$p<0.01$} \\
\hline \multicolumn{6}{|l|}{ Sex } \\
\hline Female & 1163 & $775(63 \%)$ & $388(35 \%)$ & $1113(47 \%)$ & $50(26 \%)$ \\
\hline \multirow[t]{2}{*}{ Male } & 1385 & $675(47 \%)$ & $710(65 \%)$ & $1246(53 \%)$ & 139 (74\%) \\
\hline & & \multicolumn{2}{|c|}{$p<0.01$} & \multicolumn{2}{|c|}{$p<0.01$} \\
\hline \multicolumn{6}{|l|}{ Ethnicity } \\
\hline Non-white & 358 & $213(15 \%)$ & $145(13 \%)$ & $328(14 \%)$ & $30(16 \%)$ \\
\hline \multirow[t]{2}{*}{ White } & 2190 & $1237(85 \%)$ & $953(87 \%)$ & $2031(86 \%)$ & $159(84 \%)$ \\
\hline & & \multicolumn{2}{|c|}{$p=0.29$} & \multicolumn{2}{|c|}{$\mathrm{p}=0.45$} \\
\hline \multicolumn{6}{|l|}{ BMI $\left(\mathrm{kg} / \mathrm{m}^{2}\right)$} \\
\hline$<25$ & 853 & $540(37 \%)$ & $313(29 \%)$ & $810(34 \%)$ & $43(23 \%)$ \\
\hline $25-30$ & 1129 & $638(44 \%)$ & $491(45 \%)$ & $1035(44 \%)$ & $94(50 \%)$ \\
\hline \multirow[t]{2}{*}{$30+$} & 566 & $272(19 \%)$ & $294(27 \%)$ & $514(22 \%)$ & $52(28 \%)$ \\
\hline & & \multicolumn{2}{|c|}{$p<0.01$} & \multicolumn{2}{|c|}{$\mathrm{p}<0.01$} \\
\hline Family and personal & & & & & \\
\hline Smoking & & & & & \\
\hline Never & 1339 & $834(58 \%)$ & $505(46 \%)$ & $1261(53 \%)$ & $78(41 \%)$ \\
\hline Former & 1011 & $535(37 \%)$ & $476(43 \%)$ & $930(39 \%)$ & $81(43 \%)$ \\
\hline Current & 198 & $81(6 \%)$ & $117(11 \%)$ & $168(7 \%)$ & $30(16 \%)$ \\
\hline & & & 0.01 & & 0.01 \\
\hline Reason for colono & & & & & \\
\hline Average risk & 2067 & $1223(84 \%)$ & $844(77 \%)$ & $1945(82 \%)$ & $122(65 \%)$ \\
\hline $\mathrm{FIT}+/ \mathrm{FOBT}+$ & 209 & $66(5 \%)$ & $143(13 \%)$ & $161(7 \%)$ & $48(25 \%)$ \\
\hline Family history & 272 & $161(11 \%)$ & $111(10 \%)$ & $253(11 \%)$ & $19(10 \%)$ \\
\hline & & & 0.01 & & 0.01 \\
\hline Lifetime NSAIDs & & & & & \\
\hline NSAID use & & & & & \\
\hline Never & 946 & $513(35 \%)$ & $433(39 \%)$ & $850(36 \%)$ & $96(51 \%)$ \\
\hline Ever & 1135 & 937 (65\%) & $665(61 \%)$ & $1509(64 \%)$ & $93(49 \%)$ \\
\hline & & & 0.04 & & 0.01 \\
\hline NSAID use frequer & & & & & \\
\hline No regular use & 946 & $513(43 \%)$ & $433(47 \%)$ & $850(43 \%)$ & $96(60 \%)$ \\
\hline Monthly & 406 & $245(20 \%)$ & $161(18 \%)$ & $383(20 \%)$ & $23(14 \%)$ \\
\hline Weekly & 292 & $162(14 \%)$ & $130(14 \%)$ & $273(14 \%)$ & $19(12 \%)$ \\
\hline Daily & 465 & $272(23 \%)$ & $193(21 \%)$ & $442(23 \%)$ & $23(14 \%)$ \\
\hline & & & 0.15 & & 0.01 \\
\hline Daily dose-years 0 & & & & & \\
\hline None & 946 & $0(0)$ & $0(0)$ & $0(0)$ & $0(0)$ \\
\hline $\mathrm{T} 1$ & 333 & $0.06(0.06)$ & $0.05(0.05)$ & $0.06(0.06)$ & $0.06(0.05)$ \\
\hline $\mathrm{T} 2$ & 669 & $0.45(0.21)$ & $0.44(0.19)$ & $0.45(0.20)$ & $0.47(0.22)$ \\
\hline T3 (high) & 600 & $4.53(6.70)$ & $4.77(5.84)$ & $4.60(6.23)$ & $5.27(8.43)$ \\
\hline & & & 0.05 & & 0.01 \\
\hline Dietary fibre intake & & & & & \\
\hline Total fibre $\ddagger \S$ & & & & & \\
\hline
\end{tabular}


Table 1 Continued

\begin{tabular}{|c|c|c|c|c|c|}
\hline & \multirow[b]{2}{*}{$\mathrm{n}$} & \multicolumn{2}{|l|}{ Polyps } & \multicolumn{2}{|c|}{ High-risk adenomas } \\
\hline & & $\begin{array}{l}\text { No } \\
n=1450(57 \%)\end{array}$ & $\begin{array}{l}\text { Yes } \\
n=1098(43 \%)\end{array}$ & $\begin{array}{l}\text { No } \\
n=2359(93 \%)\end{array}$ & $\begin{array}{l}\text { Yes } \\
n=189(7 \%)\end{array}$ \\
\hline Q1 (low) & 548 & $11.01(2.58)$ & $10.51(2.65)$ & $10.87(2.60)$ & $10.00(2.78)$ \\
\hline Q2 & 545 & $16.75(1.41)$ & $16.98(1.34)$ & $16.84(1.39)$ & $16.85(1.34)$ \\
\hline Q3 & 549 & $22.14(1.91)$ & $22.04(1.75)$ & $22.10(1.85)$ & $22.11(1.90)$ \\
\hline Q4 (high) & 552 & $33.88(8.23)$ & $33.59(8.89)$ & $33.83(8.54)$ & $32.58(6.67)$ \\
\hline \multicolumn{6}{|c|}{ Soluble fibre‡ף } \\
\hline Q1 (low) & 547 & $3.69(0.86)$ & $3.61(0.87)$ & $3.68(0.85)$ & $3.38(0.99)$ \\
\hline Q2 & 551 & $5.61(0.46)$ & $5.66(0.46)$ & $5.63(0.46)$ & $5.56(0.49)$ \\
\hline Q3 & 545 & $7.32(0.59)$ & $7.33(0.56)$ & $7.32(0.58)$ & $7.35(0.53)$ \\
\hline Q4 (high) & 551 & $11.17(2.79)$ & $11.32(3.20)$ & $11.22(2.96)$ & $11.16(2.45)$ \\
\hline Q3 & 548 & $14.72(1.23)$ & $14.70(1.22)$ & $14.72(1.22)$ & $14.63(1.28)$ \\
\hline Q4 (high) & 554 & $22.67(5.54)$ & $22.58(5.79)$ & $22.69(5.69)$ & $21.55(4.08)$ \\
\hline & & \multicolumn{2}{|c|}{$\mathrm{p}=0.39$} & \multicolumn{2}{|c|}{$p=0.09$} \\
\hline
\end{tabular}

${ }^{*} \mathrm{p}$-Values from Pearson's $\chi^{2}$ test of independence.

tTertile cut-offs for NSAID use were: $4.5 \times 10^{-5}-00.164,0.165-0.894$ and $\geq 0.904$ daily dose-years.

¥Missing questionnaire data on fibre intake lead to reduced sample size $(n=2194)$.

§Quartile cut-offs for total dietary fibre intake were: $\leq 14.3,14.31-19.14,19.15-25.51$ and $\geq 25.52 \mathrm{~g} /$ day.

१Quartile cut-offs for dietary insoluble fibre intake were: $\leq 9.36,9.37-12.72,12.73-16.96$ and $\geq 16.98 \mathrm{~g} /$ day.

** Quartile cut-offs for dietary soluble fibre intake were: $\leq 4.83,4.84-6.42,6.43-8.44$ and $\geq 8.45 \mathrm{~g} / \mathrm{day}$.

BMI, body mass index; FIT, faecal immunochemical test; FOBT, faecal occult blood test; NSAIDs, non-steroidal anti-inflammatory drugs.

outcomes. All analyses were performed using STATA 14 (College Station, Texas, USA).

\section{RESULTS}

In examining baseline characteristics of the study population by outcome, statistically significant differences were observed across population subgroups of interest, including age, sex, BMI, smoking status and reason for colonoscopy (table 1). We also observed statistically significant differences for the outcome of HRAPs across subgroups of NSAID use based on the number of NSAIDs used and quartiles of daily dose-years of NSAID use $(p<0.05)$. No significant differences by Pearson's $\chi^{2}$ test were observed for either colorectal outcome across quartiles of fibre intake ( $p>0.05$ for all).

When investigating associations between the presence of colorectal polyps and dietary fibre intake (table 2), we observed an inverse association between high dietary fibre intake (highest versus lowest quartile of fibre intake) and both any polyps $(n=863)$ and HRAPS $(n=140)$, although the effect was only statistically significant with HRAPs (adjusted OR $=0.50,95 \% \mathrm{CI}$ : 0.29 to 0.86 ). This inverse association with the presence of HRAPs was also seen with high intake of both soluble $(\mathrm{OR}=0.51$, $95 \% \mathrm{CI}: 0.30$ to 0.88$)$ and insoluble $(\mathrm{OR}=0.51,95 \% \mathrm{CI}: 0.30$ to 0.86 ) fibres when comparing the highest to lowest quartiles of fibre intake, after adjusting for potential confounders. Although the inverse association between high dietary fibre intake and presence of any polyps was not statistically significant, a similar trend was still observed and this effect was stronger for soluble fibre $(\mathrm{OR}=0.69,95 \% \mathrm{CI}: 0.53$ to 0.89$)$ for the highest versus lowest quartile of intake. With respect to NSAID use, participants who had ever used NSAIDs also showed a statistically significant inverse association with HRAPS $(n=189, \mathrm{OR}=0.65$, $95 \% \mathrm{CI}: 0.47$ to 0.89 ). In using daily dose-years as a representative measure of lifetime NSAID use, we observed strong inverse effects for the presence of HRAPs in the lowest $(\mathrm{OR}=0.60$, 95\% CI: 0.39 to 0.92$)$ and highest $(\mathrm{OR}=0.63,95 \% \mathrm{CI}: 0.40$ to $1.00)$ tertiles of use. When examining the frequency of NSAID use, daily use showed the strongest effect on HRAPs $(\mathrm{OR}=0.53$, 95\% CI: 0.32 to 0.86 ), whereas weekly and monthly use also showed inverse effects, with monthly use being statistically significant $(\mathrm{OR}=0.60,95 \% \mathrm{CI}: 0.37$ to 0.95$)$. Similar to dietary fibre intake, this inverse effect of NSAID use was stronger for HRAPs as an outcome than for polyps $(n=1098)$.

In further analyses, we tested for interaction by sex, BMI, age, ethnicity, reason for colonoscopy or smoking status on the association between dietary fibre intake or NSAID use and presence of polyps or HRAPs. For all three measures of dietary fibre intake (total, soluble and insoluble), there was a statistically significant interaction by BMI and ethnicity on the presence of polyps at screening. In a stratified analysis based on clinically relevant categories of BMI (normal: BMI $<25 \mathrm{~kg} / \mathrm{m}^{2}$, overweight: $25 \mathrm{~kg}$ / $\mathrm{m}^{2} \leq \mathrm{BMI}<30 \mathrm{~kg} / \mathrm{m}^{2}$ and obese: BMI $\geq 30 \mathrm{~kg} / \mathrm{m}^{2}$ ), an inverse effect of dietary fibre intake (total, soluble and insoluble) on colorectal polyps was only evident in the highest quartile of fibre intake in obese participants (table 3). When stratified by ethnicity (white versus non-white), we observed a stronger effect of total dietary fibre $\left(\mathrm{p}_{\text {interaction }}=0.03\right)$ and particularly insoluble fibre $\left(\mathrm{p}_{\text {interaction }}=0.01\right)$ among non-white participants (table 4$)$.

\section{DISCUSSION}

In this cross-sectional analysis, we observed a strong inverse association between increased dietary fibre intake or daily NSAID 


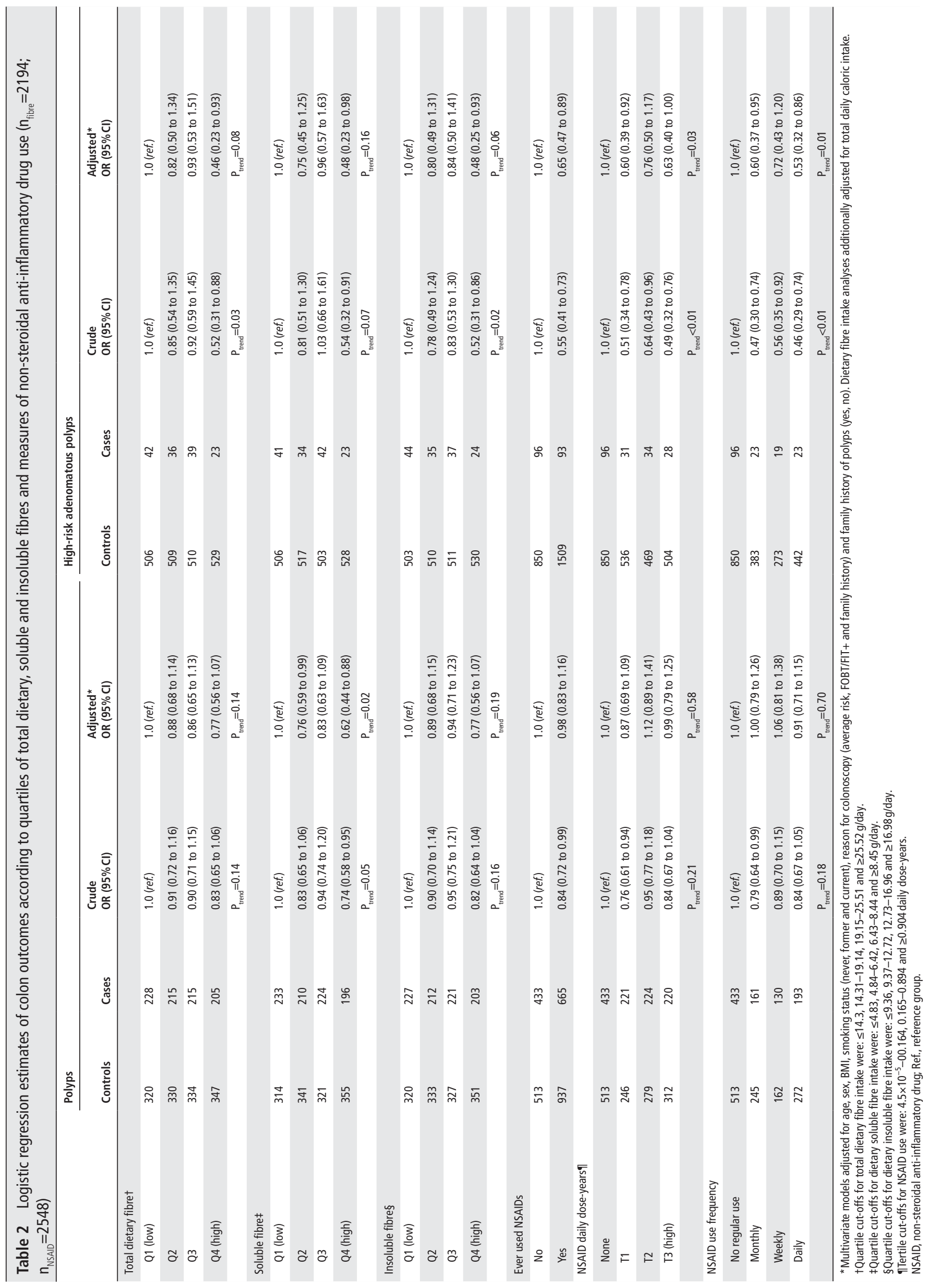


Table 3 BMI-stratified logistic regression estimates of polyps according to total, soluble and insoluble dietary fibre quartiles ( $n=2194$ )

\begin{tabular}{|c|c|c|c|c|c|c|c|c|c|c|}
\hline \multirow[b]{3}{*}{ Polyps } & \multicolumn{9}{|l|}{ BMI } & \multirow[b]{3}{*}{$\mathbf{p}_{\text {interaction }}$} \\
\hline & \multicolumn{3}{|c|}{ Normal weight $(n=732)$} & \multicolumn{3}{|c|}{ Overweight $(n=974)$} & \multicolumn{3}{|c|}{ Obese $(n=488)$} & \\
\hline & Controls & Cases & $\begin{array}{l}\text { Adjusted* } \\
\text { OR }(95 \% \mathrm{Cl})\end{array}$ & Controls & Cases & $\begin{array}{l}\text { Adjusted* } \\
\text { OR }(95 \% \mathrm{Cl})\end{array}$ & Controls & Cases & $\begin{array}{l}\text { Adjusted* } \\
\text { OR }(95 \% \mathrm{Cl})\end{array}$ & \\
\hline \multicolumn{11}{|c|}{ Total fibret } \\
\hline Q1 & 113 & 66 & 1.0 (ref.) & 139 & 88 & 1.0 (ref.) & 68 & 74 & 1.0 (ref.) & 0.02 \\
\hline Q2 & 124 & 49 & 0.62 (0.39 to1.01) & 149 & 109 & 1.15 (0.78 to 1.70$)$ & 57 & 57 & 0.84 (0.49 to1.45) & \\
\hline Q3 & 118 & 62 & 0.80 (0.49 to1.31) & 158 & 96 & 0.96 (0.63 to1.46) & 58 & 57 & 0.76 (0.42 to 1.36$)$ & \\
\hline \multirow[t]{2}{*}{ Q4 } & 132 & 68 & 0.71 (0.40 to 1.27 ) & 142 & 93 & 1.06 (0.64 to1.75) & 73 & 44 & 0.41 (0.20 to 0.83$)$ & \\
\hline & & & $P_{\text {trend }}=0.39$ & & & $P_{\text {trend }}=0.91$ & & & $P_{\text {trend }}=0.02$ & \\
\hline \multicolumn{11}{|c|}{ Soluble fibre $\ddagger$} \\
\hline Q1 & 117 & 62 & 1.0 (ref.) & 132 & 93 & 1.0 (ref.) & 65 & 78 & 1.0 (ref.) & 0.01 \\
\hline Q2 & 128 & 56 & 0.75 (0.47 to 1.22$)$ & 153 & 103 & 0.89 (0.60 to1.32) & 60 & 51 & 0.57 (0.33 to 0.99$)$ & \\
\hline Q3 & 117 & 65 & 0.89 (0.54 to 1.45$)$ & 151 & 97 & 0.81 (0.53 to1.24) & 53 & 62 & 0.75 (0.41 to1.35) & \\
\hline \multirow[t]{2}{*}{ Q4 } & 125 & 62 & 0.74 (0.41 to 1.35$)$ & 152 & 93 & 0.79 (0.47 to1.33) & 78 & 41 & $0.26(0.12$ to 0.56$)$ & \\
\hline & & & $P_{\text {trend }}=0.48$ & & & $P_{\text {trend }}=0.32$ & & & $P_{\text {trend }}<0.01$ & \\
\hline \multicolumn{11}{|c|}{ Insoluble fibre§ } \\
\hline Q1 & 112 & 63 & 1.0 (ref.) & 142 & 89 & 1.0 (ref.) & 66 & 75 & 1.0 (ref.) & 0.02 \\
\hline Q2 & 129 & 48 & 0.61 (0.38 to 0.99 ) & 145 & 105 & 1.19 (0.80 to1.77) & 59 & 59 & 0.85 (0.49 to1.46) & \\
\hline Q3 & 112 & 69 & 1.01 (0.62 to 1.65$)$ & 158 & 98 & 1.04 (0.69 to1.58) & 57 & 54 & 0.67 (0.37 to1.21) & \\
\hline \multirow[t]{2}{*}{ Q4 } & 134 & 65 & 0.67 (0.38 to 1.21$)$ & 143 & 94 & 1.14 (0.70 to1.86) & 74 & 44 & 0.39 (0.19 to 0.77$)$ & \\
\hline & & & $P_{\text {trend }}=0.51$ & & & $P_{\text {trend }}=0.79$ & & & $\mathrm{P}_{\text {trend }}<0.01$ & \\
\hline
\end{tabular}

*Multivariate models adjusted for age, sex, BMI, total daily caloric intake, smoking status (never, former and current), reason for colonoscopy (average risk, FOBT/FIT+ and family history) and family history of polyps (yes versus no).

tQuartile cut-offs for total dietary fibre intake were: $\leq 14.3,14.31-19.14,19.15-25.51$ and $\geq 25.52 \mathrm{~g} /$ day.

$\ddagger Q$ uartile cut-offs for dietary soluble fibre intake were: $\leq 4.83,4.84-6.42,6.43-8.44$ and $\geq 8.45 \mathrm{~g} / \mathrm{day}$.

$\S$ Quartile cut-offs for dietary insoluble fibre intake were: $\leq 9.36,9.37-12.72,12.73-16.96$ and $\geq 16.98 \mathrm{~g} /$ day.

BMI, body mass index; Ref., reference group.

use and the occurrence of HRAPs in this population screened for colorectal cancer. The effect of dietary fibre intake was found to be modified by BMI and ethnicity, with stronger inverse associations observed in obese and non-white ethnicity individuals, respectively.

Results of this study demonstrating an inverse association between increased dietary fibre intake and colorectal polyps, particularly HRAPS, are consistent with other similar observational studies. ${ }^{21-26}$ However, this inverse effect of increased dietary fibre on incidence or recurrence of colorectal adenomas has not been observed in randomised controlled trials. ${ }^{13} 142728$ It is hypothesised that the lack of effect of dietary fibre in these trials can be attributed to the studies being too short in follow-up or that the fibre intervention did not contain enough fibre to show an effect. ${ }^{10}$ Indeed, a second analysis of results from the US Polyp Prevention Trial ${ }^{13}$ showed that a statistically significant reduction in adenoma recurrence was associated with increased dietary fibre intake only among those who were the most adherent to the intervention. ${ }^{29}$ Furthermore, some dietary interventions only increased the intake of total dietary fibre to $25-27 \mathrm{~g} / \mathrm{day},{ }^{14}{ }^{30}$ whereas the highest quartile of total dietary fibre intake in our study was $\geq 25.52 \mathrm{~g} /$ day, with a mean of $33.77 \mathrm{~g} /$ day, which is more consistent with observational studies demonstrating an inverse association between dietary fibre and adenoma risk. ${ }^{22} 2426$ While it is challenging to compare self-reported fibre intake and an intervention dose, the discrepancy suggests that higher levels of fibre than were administered in the intervention trials may be necessary to observe an impact on the incidence of polyps in a relatively short period.
Soluble fibre differs from insoluble fibre in that it tends to attract water and form gels. This then leads to decreased transit time and nutrient absorption, including glucose, and can decrease cholesterol synthesis through its fermentation in the intestines. ${ }^{31}$ Contrastingly, insoluble fibre tends to pass unaltered through the digestive system, but causes bulking of the stool by retaining water and binds to bile acids and carcinogens, while also decreasing transit time. ${ }^{31} 32$ Soluble fibre has previously been associated with reduced cardiovascular disease ${ }^{33}$ and diabetes ${ }^{34}$, and the mechanisms are hypothesised to be due to the decreased intestinal absorption and reduced cholesterol synthesis. To our knowledge, only one previous study has investigated the effect of fibre intake on colorectal adenomas by soluble and insoluble fibres. Results of this study on distal colorectal adenomas in men only demonstrated a protective association with soluble fibre, but not insoluble fibre. ${ }^{35}$ Similarly, results from this study showed a stronger effect of dietary intake soluble fibre than insoluble fibre, and it is possible that the above mechanisms can be attributed to this.

The effect of dietary fibre was found to be modified by both BMI and ethnicity in our results, with the inverse effects of fibre being more prominent in obese (BMI $\geq 30 \mathrm{~kg}$ / $\mathrm{m}^{2}$ ) and non-white participants, respectively. Increased BMI represents an independent risk factor for colorectal polyps and adenomas. ${ }^{3637}$ Studies have shown that Hispanic individuals are at similar ${ }^{3839}$ or lower risk ${ }^{40}$ of colorectal adenomas compared with white individuals, whereas black individuals are at an increased risk. ${ }^{38}$ Our study was limited in that there were very few non-white participants $(n=358)$ compared with 
Table 4 Ethnicity-stratified logistic estimates of high-risk adenomatous polyps according to total, soluble and insoluble dietary fibre quartiles $(n=2194)$

\begin{tabular}{|c|c|c|c|c|c|c|c|}
\hline \multirow[b]{3}{*}{ Polyps } & \multicolumn{6}{|l|}{ Ethnicity } & \multirow[b]{3}{*}{$\mathbf{p}_{\text {interaction }}$} \\
\hline & \multicolumn{3}{|c|}{ White $(n=1920)$} & \multicolumn{3}{|c|}{ Non-white $(n=274)$} & \\
\hline & Controls & Cases & $\begin{array}{l}\text { Adjusted* } \\
\text { OR }(95 \% \mathrm{Cl})\end{array}$ & Controls & Cases & $\begin{array}{l}\text { Adjusted* } \\
\text { OR }(95 \% \mathrm{Cl})\end{array}$ & \\
\hline \multicolumn{8}{|c|}{ Total fibret } \\
\hline Q1 & 272 & 194 & 1.0 (ref.) & 48 & 34 & 1.0 (ref.) & 0.03 \\
\hline Q2 & 293 & 193 & 0.92 (0.70 to1.22) & 37 & 22 & 0.67 (0.31 to1.44) & \\
\hline \multirow[t]{2}{*}{ Q4 } & 297 & 186 & 0.88 (0.61 to1.25) & 50 & 19 & 0.33 (0.12 to 0.89 ) & \\
\hline & & & $P_{\text {trend }}=0.57$ & & & $P_{\text {trend }}=0.01$ & \\
\hline \multicolumn{8}{|c|}{ Soluble fibreł } \\
\hline Q1 & 269 & 199 & 1.0 (ref.) & 45 & 34 & 1.0 (ref.) & 0.05 \\
\hline Q2 & 301 & 190 & 0.82 (0.62 to1.08) & 40 & 20 & $0.45(0.20$ to 0.97$)$ & \\
\hline Q1 & 271 & 194 & 1.0 (ref.) & 49 & 33 & 1.0 (ref.) & 0.01 \\
\hline Q2 & 293 & 187 & 0.91 (0.69 to1.21) & 40 & 25 & 0.78 (0.37 to1.63) & \\
\hline Q3 & 284 & 204 & 1.05 (0.78 to 1.41$)$ & 43 & 17 & 0.41 (0.17 to 0.94$)$ & \\
\hline \multirow[t]{2}{*}{ Q4 } & 300 & 187 & 0.88 (0.62 to 1.25$)$ & 51 & 16 & 0.28 (0.11 to 0.76$)$ & \\
\hline & & & $P_{\text {trend }}=0.73$ & & & $\mathrm{P}_{\text {trend }}<0.01$ & \\
\hline
\end{tabular}

*Multivariate models adjusted for age, sex, BMI, total daily caloric intake, smoking status (never, former and current), reason for colonoscopy (average risk, FOBT/FIT+ and family history) and family history of polyps (yes versus no).

tQuartile cut-offs for total dietary fibre intake were: $\leq 14.3,14.31-19.14,19.15-25.51$ and $\geq 25.52 \mathrm{~g} /$ day.

$\ddagger$ Quartile cut-offs for dietary soluble fibre intake were: $\leq 4.83,4.84-6.42,6.43-8.44$ and $\geq 8.45 \mathrm{~g} /$ day.

$\S$ Quartile cut-offs for dietary insoluble fibre intake were: $\leq 9.36,9.37-12.72,12.73-16.96$ and $\geq 16.98 \mathrm{~g} /$ day.

Ref., reference group.

white participants $(n=2190)$ such that all non-white participants were grouped together for analysis purposes, and we were underpowered to determine the effects of any individual ethnicity. To our knowledge, no other studies have investigated the effect modification of the association between dietary fibre and presence of colorectal polyps. However, the present results indicate that there may be certain subgroups in the population (obese and non-white) that may further benefit from increased fibre intake.

In this study, we observed an inverse association between ever use of NSAIDs and the presence of HRAPs. On further investigation of NSAID use by tertiles of daily dose-years, we observed statistically significant inverse associations between the first and third tertiles of use, but a protective trend overall. Since both duration and frequency of NSAID use are taken into account in determining daily dose-years of NSAID use, we examined the duration and frequency of use of participants who fell in each tertile of daily dose-years of NSAID use. We found that those in the first tertile consisted predominantly of monthly (or less than monthly) users of NSAIDs, but in longer durations and those in the third tertile were predominantly daily NSAID users (data not shown). This was reflected in our analysis by frequency of NSAID use, where the strongest effects were observed in daily and monthly users. Results from our study agree with previous observational studies that have shown a beneficial effect of NSAID use on the incidence and recurrence of colorectal adenomas, ${ }^{41}{ }^{42}$ including a meta-analysis of four randomised controlled trials showed a statistically significant reduced relative risk $(0.83,95 \% \mathrm{CI}$ : 0.72 to 0.96$)$ of any adenoma with any dose of aspirin compared with the placebo. ${ }^{43}$

While our results are encouraging from a primary prevention perspective, this study is limited by the cross-sectional nature of the analysis, which only captures the prevalence of past-year dietary fibre intake, and regular adult NSAID use and colorectal polyps in this population and thus, a temporal relationship cannot be established. Furthermore, because this was a post hoc analysis, our exposure measurements were not as detailed as possible and thus, patterns of dietary fibre intake and NSAID use could not be fully established to better understand the nature of the observed inverse associations. All of the exposure assessments in this study were based on self-reported data; thus, measurement error is another limitation of the study. Selection bias may play a role in these results because participants were passively recruited from the CCSC. Thus, there could be underlying reasons related to colonoscopy outcomes or exposure status as to why an individual would choose to participate, such as a healthy participant bias, despite recruitment occurring precolonoscopy. Lastly, this study population was underpowered to explore some of the subgroup analyses, particularly by reason for colonoscopy as there were only 209 participants who were FIT/FOB test-positive, and 272 participants had a family history of colorectal cancer. As these individuals are at an increased risk of developing colorectal cancer (family history) or having colorectal cancer at screening (FIT/FOB test-positive), future research in these groups can be pivotal for primary prevention strategies. 
Overall, we observed a significant inverse association between increased dietary fibre and the presence of HRAPs in a population undergoing colorectal cancer screening, with stronger effects being observed in obese and non-white ethnicity individuals. NSAID use was also inversely associated with the presence of HRAPs at colonoscopy. Results of this study can be used to inform future primary prevention strategies in colorectal cancer screening.

\section{What is already known on this subject}

Increased dietary fibre intake and use of non-steroidal antiinflammatory drugs have generally been associated with a decreased risk of colorectal cancer. However, this has not been consistently demonstrated, and results on their association with the incidence of colorectal polyps remain unknown.

\section{What this study adds}

Results from this study suggest that increased dietary fibre (total, soluble and insoluble) is statistically significantly associated with a decreased presence of high-risk adenomatous polyps at screening (quartile 4 vs quartile 1). Similarly, ever, monthly and daily non-steroidal anti-inflammatory drug use were associated with a decreased risk of high-risk adenomatous polyps at screening.

Acknowledgements We would like to thank the patients of the Forzani \& MacPhail Colon Cancer Screening Centre who consent to participation within the CCSC Biorepository, Calgary, Canada.

Contributors SEM and RJH were responsible for the conception and design of the original study and data collection from the Forzani \& MacPhail Colon Cancer Screening Centre. ST collected the data. DRB conceived the idea and design of the present analysis. ES and MTW carried out the analysis of the data. ES wrote the manuscript. SEM, RJH and DRB contributed to meaningful discussion and critical review of the manuscript. All authors have read and approved the final manuscript.

Funding This work was supported by a Career Development Award in Prevention Research (no 703917) from the Canadian Cancer Society held by DRB.

Competing interests None declared.

Ethics approval Health Research Ethics Board of Alberta.

Provenance and peer review Not commissioned; externally peer reviewed.

Open Access This is an Open Access article distributed in accordance with the Creative Commons Attribution Non Commercial (CC BY-NC 4.0) license, which permits others to distribute, remix, adapt, build upon this work non-commercially, and license their derivative works on different terms, provided the original work is properly cited and the use is non-commercial. See: http://creativecommons.org/ licenses/by-nc/4.0/

(c) Article author(s) (or their employer(s) unless otherwise stated in the text of the article) 2017. All rights reserved. No commercial use is permitted unless otherwise expressly granted.

\section{REFERENCES}

1 Canadian Cancer Statistics. Canadian cancer society's advisory committee on cancer statistics. Toronto, ON: Canadian Cancer Society, 2015.

2 Aune D, Chan DS, Lau R, et al. Dietary fibre, whole grains, and risk of colorectal cancer: systematic review and dose-response meta-analysis of prospective studies. BMJ 2011;343:d6617.

3 Park Y, Hunter DJ, Spiegelman D, et al. Dietary fiber intake and risk of colorectal cancer: a pooled analysis of prospective cohort studies. JAMA 2005;294:2849-57.

4 Moore MA, Park CB, Tsuda H. Soluble and insoluble fiber influences on cancer development. Crit Rev Oncol Hematol 1998:27:229-42.

5 Wakeman C, Keenan J, Eteuati J, et al. Chemoprevention of colorectal neoplasia. ANZ J Surg 2015.

6 Eberhart CE, Coffey RJ, Radhika A, et al. Up-regulation of cyclooxygenase 2 gene expression in human colorectal adenomas and adenocarcinomas. Gastroenterology 1994;107:1183-8
7 Ahnen DJ. Colon cancer prevention by NSAIDs: what is the mechanism of action? Eur J Surg Supp/ 1998:111-4.

8 Muto T, Bussey HJ, Morson BC. The evolution of cancer of the colon and rectum. Cancer 1975:36:2251-70.

9 Fenoglio-Preiser CM, Hutter RV. Colorectal polyps: pathologic diagnosis and clinical significance. CA Cancer J Clin 1985;35:322-44.

10 Asano T, McLeod RS. Dietary fibre for the prevention of colorectal adenomas and carcinomas. Cochrane Database Syst Rev 2002:CD003430. CD003430.

11 Ben Q, Sun Y, Chai R, et al. Dietary fiber intake reduces risk for colorectal adenoma: a meta-analysis. Gastroenterology 2014;146:689-99.

12 Fuchs CS, Giovannucci EL, Colditz GA, et al. Dietary fiber and the risk of colorectal cancer and adenoma in women. N Eng/ J Med 1999;340:169-76.

13 Schatzkin A, Lanza E, Corle D, et al. Lack of effect of a low-fat, high-fiber diet on the recurrence of colorectal adenomas. polyp prevention trial study group. N Eng/ J Med 2000:342:1149-55

14 Alberts DS, Martínez ME, Roe DJ, et al. Lack of effect of a high-fiber cereal supplement on the recurrence of colorectal adenomas. Phoenix Colon Cancer Prevention Physicians' Network. N Engl J Med 2000;342:1156-62.

15 Jacobs ET, Lanza E, Alberts DS, et al. Fiber, sex, and colorectal adenoma: results of a pooled analysis. Am J Clin Nutr 2006;83:343-9.

16 Wang Y, Zhang FC, Wang YJ. The efficacy and safety of non-steroidal antiinflammatory drugs in preventing the recurrence of colorectal adenoma: a meta-analysis and systematic review of randomized trials. Colorectal Dis 2015:17:188-96.

17 Chubak J, Kamineni A, Buist DSM, et al. Aspirin Use for the Prevention of Colorectal Cancer: An Updated Systematic Evidence Review for the U.S. Preventive Services Task Force. Rockville, MD, 2015

18 Toward optimized practice (TOP) working group for colorectal cancer screening Colorectal Cancer Screening: Clinical Practice Guideline. Edmonton, AB: Toward Optimized Practice, 2013.

19 Subar AF, Thompson FE, Kipnis V, et al. Comparative validation of the Block, Willett, and National Cancer Institute food frequency questionnaires : the Eating at America's Table Study. Am J Epidemiol 2001;154:1089-99.

20 Csizmadi I, Kahle L, Ullman R, et al. Adaptation and evaluation of the national cancer institute's diet history questionnaire and nutrient database for canadian populations. Public Health Nutr 2007; 10:88-96.

21 Kunzmann AT, Coleman HG, Huang WY, et al. Dietary fiber intake and risk of colorectal cancer and incident and recurrent adenoma in the prostate, lung, colorectal, and ovarian cancer screening Trial. Am I Clin Nutr 2015:102:881-90.

22 Fu Z, Shrubsole MJ, Smalley WE, et al. Lifestyle factors and their combined impact on the risk of colorectal polyps. Am J Epidemiol 2012;176:766-76.

23 Tantamango YM, Knutsen SF, Beeson L, et al. Association between dietary fiber and incident cases of colon polyps: the adventist health study. Gastrointest Cancer Res 2011:4:161-7

24 Northwood EL, Elliott F, Forman D, et al. Polymorphisms in xenobiotic metabolizing enzymes and diet influence colorectal adenoma risk. Pharmacogenet Genomics 2010;20:315-26.

25 Lieberman DA, Prindiville S, Weiss DG, et al. Risk factors for advanced colonic neoplasia and hyperplastic polyps in asymptomatic individuals. JAMA 2003:290:2959-67.

26 Peters U, Sinha R, Chatterjee N, et al. Dietary fibre and colorectal adenoma in a colorectal cancer early detection programme. Lancet 2003;361:1491-5.

27 Bonithon-Kopp C, Kronborg O, Giacosa A, et al. Calcium and fibre supplementation in prevention of colorectal adenoma recurrence: a randomised intervention trial. European Cancer Prevention Organisation Study Group. Lancet 2000;356:1300-6.

28 MacLennan R, Macrae F, Bain C, et al. Randomized trial of intake of fat, fiber, and beta carotene to prevent colorectal adenomas. J Nat/ Cancer Inst 1995;87:1760-6.

29 Sansbury LB, Wanke K, Albert PS, et al. The effect of strict adherence to a high-fiber, high-fruit and -vegetable, and low-fat eating pattern on adenoma recurrence. Am J Epidemiol 2009;170:576-84.

30 Robertson DJ, Sandler RS, Haile R, et al. Fat, fiber, meat and the risk of colorectal adenomas. Am J Gastroenterol 2005;100:2789-95.

31 James SL, Muir JG, Curtis SL, et al. Dietary fibre: a roughage guide. Intern Med J 2003:33:291-6.

32 Spiller RC. Pharmacology of dietary fibre. Pharmacol Ther 1994;62:407-27.

33 Kushi LH, Meyer KA, Jacobs DR. Cereals, legumes, and chronic disease risk reduction: evidence from epidemiologic studies. Am J Clin Nutr 1999;70:451S-8.

34 Lafrance L, Rabasa-Lhoret R, Poisson D, et al. Effects of different glycaemic index foods and dietary fibre intake on glycaemic control in type 1 diabetic patients on intensive insulin therapy. Diabet Med 1998:15:972-8.

35 Platz EA, Giovannucci E, Rimm EB, et al. Dietary fiber and distal colorectal adenoma in men. Cancer Epidemiol Biomarkers Prev 1997:6:661-70.

36 Omata F, Deshpande GA, Ohde S, et al. The association between obesity and colorectal adenoma: systematic review and meta-analysis. Scand I Gastroenterol 2013:48:136-46

37 Okabayashi K, Ashrafian H, Hasegawa H, et al. Body mass index category as a risk factor for colorectal adenomas: a systematic review and meta-analysis. Am J Gastroenterol 2012;107:1175-85. quiz 86. 
38 Lieberman DA, Williams JL, Holub JL, et al. Race, ethnicity, and sex affect risk for polyps $>9 \mathrm{~mm}$ in average-risk individuals. Gastroenterology 2014;147:351-8. quiz e14-5.

39 Thoma MN, Jimenez Cantisano BG, Hernandez AV, et al. Comparison of adenoma detection rate in hispanics and whites undergoing first screening colonoscopy: a retrospective chart review. Gastrointest Endosc 2013;77:430-5.

40 Zheng XE, Li T, Lipka S, et al. Location-dependent ethnic differences in the risk of colorectal adenoma: a retrospective multiethnic study. J Clin Gastroenterol 2014;48:e1-7.
41 Johnson CC, Hayes RB, Schoen RE, et al. Non-steroidal anti-inflammatory drug use and colorectal polyps in the prostate, lung, colorectal, and ovarian cancer screening trial. Am J Gastroenterol 2010;105:2646-55.

42 Tangrea JA, Albert PS, Lanza E, et al. Non-steroidal anti-inflammatory drug use is associated with reduction in recurrence of advanced and non-advanced colorectal adenomas (United States). Cancer Causes Control 2003;14:403-11.

43 Cole BF, Logan RF, Halabi S, et al. Aspirin for the chemoprevention of colorectal adenomas: meta-analysis of the randomized trials. J Nat/ Cancer Inst 2009;101:256-66. 